\section{LA MÍSTICA EN LAS OBRAS DE JORGE LUIS BORGES}

MYSTIC IN WORKS BY JORGE LUIS BORGES

Ahmad Husein Issa Al-Afif Mohammad Daher Ababneh

Universidad de Jordania

RESUMEN:

Abstract:

Muchos cuentos del autor argentino Jorge Many tales by Argentinian author Jorge Luis Luis Borges contienen cierto matiz religioso Borges have certain religious nuance which que podría vincularse al movimiento literario could be related to the literary movemen conocido como mística. En este artículo se known as Mystic. In this article some of these analizarán algunos de esos aspectos que aspects which appear in his works will be aparecen en su obra. analysed.

\section{Palabras claves:}

Jorge Luis Borges, cuento, místico.

\section{KeY WORD:}

Jorge Luis Borges, tale, mystic.
En las obras de Jorge Luís Borges podemos encontrar varios textos que están impregnados de un fino sentido místico. Algunos de los cuentos borgianos residen en el campo de la mística islámica (el sufismo) como la otra vertiente de la religión musulmana. Un dato que corrobora este interés es la afirmación oral del escritor argentino: “[...] He estado también muy interesado por el sufismo. De modo que todo eso ha influido en mí, pero no sé hasta dónde. He estudiado esas religiones, o esas filosofías orientales como posibilidades para el pensamiento o para la conducta, o las he estudiado desde un punto de vista imaginativo para la literatura [...]" (Guibert, 1986: 335).

Borges en otra entrevista con Willis Barnstone, le confesó que había vivido la experiencia mística dos veces en su vida:

En mi vida [...] he tenido dos experiencias místicas, y no puedo decirlas porque lo que me sucedió no es para ser puesto en palabras [...] fue asombroso, deslumbrante. Me sentí avasallado, atónito. Tuve la sensación de vivir no en el tiempo sino fuera del tiempo [...]. Escribí poemas sobre ello, pero son poemas normales y no pueden decir la experiencia. No puedo decírsela a ud., ya que ni siquiera puedo repetírmela a mí mismo, pero tuve esa experiencia, y la tuve dos veces, y acaso me rea otorgado volver a tenla antes de morir (Barnstone, 1982: 11, López-Baralt y Báez, 1996: 256).

Borges en algunos textos suyos desarrolla la experiencia mística en los personajes de sus cuentos que empiezan su búsqueda febril de la evidencia escondida. Los escritos de Borges se interesan por un proceso de búsqueda que llevan a un descubrimiento que convive con el carácter fantástico de la producción borgiana. En los cuentos de Borges, los personajes abandonan las cosas visibles y palpables en un espacio de búsqueda espiritual. Borges emplea la mística en sus obras como camino de la verdad que siempre exige una búsqueda espiritual permanente. Por esto vemos que en algunos cuentos los personajes experimentan una aventura espiritual para descubrir esta verdad absoluta.

El cuento titulado El acercamiento a Almotásim contiene muchos aspectos del sufismo. El autor nos da a conocer una crítica a modo de reseña de las dos versiones de una novela publicada en Bombay, cuyo autor es Mir Bahadur Alí. El narrador trata primero los personajes así como el aspecto formal de la novela, y después amplifica su análisis de los dos primeros capítulos. En adelante, y mediante una especie de enumeración desordenada, se presentan detalles de los capítulos restantes. Sin embargo, la idea central de la novela se explica en estas palabras: “[...] un hombre, el estudiante incrédulo y fugitivo [...] El estudiante resuelve dedicar su vida a encontrarlo" (Borges, Historia de la eternidad: 139-140). Podemos considerar, que la búsqueda mística constituye el eje de este cuento, el narrador mismo interpreta este argumento como una verdadera metáfora de la búsqueda mística: “[...] la insaciable busca de un alma a través de los delicados reflejos que ésta ha dejado en otras: en el principio, el tenue rastro de una 
sonrisa o de una palabra; en el fin, esplendores diversos y crecientes de la razón, de la imaginación y del bien" (Borges, Historia de la eternidad: 139-140).

Borges, como escritor intelectual, no olvida relacionar su cuento con otra obra que tiene desde su perspectiva algo en común con el cuento. Borges en una nota al pie de página, detalla el contenido de la obra Coloquio de los pájaros, del sufí persa Fârîd ad-Dîn `At:âr, y su vinculación con la novela de Bahadur. Como han señalado tanto Ronald Christ como Arturo Echavarría: "Esta nota al calce ofrece por implicación un dato que la reseña misma oculta: que el propio protagonista de la novela de Bahadur es el misterioso Almotásim y que la novela es el recuento de una auto- purificación" (Echavarría, 1983: 194-195; González Pérez, 1995: 216)

La comparación de la historia de 'At:âr con la de Bahadur Ali es evidentemente justificable pues Borges resume el poema del sufí persa en una nota al pie:

El remoto rey de los pájaros, el Simurg, deja caer en el centro de la China una pluma espléndida; los pájaros resuelven buscarlo, hartos de su antigua anarquía. Saben que el nombre de su rey quiere decir treinta pájaros; saben que su alcázar está en el Kaf, la montaña circular que rodea la tierra. Acometen la casi infinita aventura; superan siete valles, o mares; el nombre del penúltimo es Vértigo; el último se llama Aniquilación. Muchos peregrinos desertan; otros perecen. Treinta, purificados por los trabajos, pisan la montaña del Simurg. Lo contemplan al fin: perciben que ellos son el Simurg y que el Simurg es cada uno de ellos y todos (Borges, Historia de la eternidad: 144).

MariaKodamanosjustificalafascinacióndeBorgesporlossufíescomo `At:âr, diciendo: Es natural que Borges se sintiera atraído por los sufíes, ya que el sufismo produjo hombres que fueron no sólo grandes místicos sino también poetas. Persia es, quizá, el país que contó con más poetas místicos, inspirados por una profunda experiencia espiritual. Los cristianos tienen a san Juan de la Cruz, un poeta místico de la misma jerarquía que Attar (Kodama de Borges, 1996: 79)

En El acercamiento a Almotásim, el estudiante emprende un viaje simbólicamente circular en busca de Almótasim, que representa la verdad absoluta y termina reencontrándose a sí mismo, o sea, reconociendo que el universo es una proyección del alma humana. En relación con el secreto de dicha circularidad, Borges advierte en una ocasión: “Los místicos pretenden que el éxtasis les revela una cámara circular con un gran libro circular de lomo continuo, que da toda la vuelta de las paredes, pero su testimonio es sospechoso; sus palabras, oscuras. Ese libro cíclico es Dios" (Borges, Ficciones: 90)

Tanto el cuento del autor indio, comoel poema del sufí persa, tratan dela identificación que se alcanza a través del descubrimiento profundo del ser, y su fusión en la esencia divina. Borges resume que la experiencia mística es una prueba experimental de Dios.
Este tipo de obsesión de pasar una experiencia mística para descubrir la clave de un misterio, se ve repetido en varios textos borgianos, donde los protagonistas hacen un auto-descubrimiento y se alimentan de la tradición mística. Observamos que algunas alusiones del autor en el cuento El acercamiento a Almótasim hacen que tanto este texto como la novela objeto de comentario, se valgan de la experiencia mística para realizarse. El autor lo expresa de varias maneras: “Esencialmente ambos escritores concuerdan: los dos indican el mecanismo policial de la obra, y su undercurrentmístico [...] Almótasim es emblema de Dios y los puntuales itinerarios del héroe son de algún modo los progresos del alma en el ascenso místico" (Borges, Historia de la eternidad: $135,142)$.

El cuento trata de un viaje ilusorio en busca de la verdad revelada en la figura de Almótasim, el cual no es más que Dios desde la óptica del sufismo. Mediante el manejo de este sistema, Borges nos sitúa frente a la práctica de la mística que es considerada como parte integrante de la religión, y que la podemos encontrar también en la historia del Islam. Gracias a este ejercicio, se produce un contacto con el Uno Absoluto en estados obtenidos por un tipo de comunicación peculiar. A la luz de lo expuesto, se nota que en el cuento de Borges, dentro del yo del personaje opera la indivisa divinidad. Borges resuelve pensar en el universo estimando las ideas místicas y religiosas por su valor estético y, por lo que encierran de singular y maravilloso. A pesar de todo, el escritor argentino no se propone exponer teorías ni sistematizar sus tesis, sino que pone a prueba artística, el conjunto de postulados de la visión mística que ha tratado de penetrar sutilmente.

Borges emplea diferentes métodos y vínculos de la absorción mística, que se ejercitan para buscar la verdad única. A diferencia del Almótasim, en el relato El Zahir, cuyo personaje principal es el narrador protagonista, el descubrimiento de un extenso mundo de símbolos ocultos se reduce a un objeto: la moneda denominada $E l$ Zahir. Se trata de una moneda inolvidable, porque siguiendo el proceso de la trama, al narrador se le ha muerto la mujer que ama antes de ver aquella moneda. Por eso, semejante circunstancia puede justificar la impresión de locura que concibe el narrador y su credibilidad de que la moneda es inolvidable. El narrador tras tomar un vaso de caña y pagarlo, descubre entre las monedas de la vuelta, el Zahir. Es en realidad, una experiencia mística y un estado de revelación por los que pasa el hombre. Aquí también se vuelve a recalcar el carácter de circularidad que se traduce en la reacción del personaje: “Vi una sufrida verja de fierro; detrás vi las baldosas negras y blancas del atrio de la Concepción. Había errado en círculo; ahora estaba a una cuadra del almacén donde me dieron el Zahir" (Borges, El Aleph: 123).

La palabra que utiliza el escritor argentino para esta moneda, proviene de la cultura arabo-islámica, y sobre el origen de esta palabra Borges anota en su cuento: “La 
creencia en el Zahir es islámica y data, al parecer, del siglo XVIII [...] Zahir, en árabe quiere decir notorio, visible; en tal sentido, es uno de los noventa y nueve nombres de Dios; la plebe, en tierras musulmanas, lo dice de los seres o cosas que tienen la terrible virtud de ser inolvidables y cuya imagen acaba por enloquecer a la gente" (Borges, El Aleph: 123)

Igual que en El acercamiento a Almótasim, este cuento tiene el mismo ideal y una misma meta que hacen que el conocimiento sea verdadero. La moneda del Zahir es la otra versión del ser contemplativo que se somete a una metamorfosis espiritual que lo iguala con el mundo. En la misma línea, Borges y citando a los cabalistas que practican un tipo peculiar de adivinación, reafirma: “Los cabalistas entendieron que el hombre es un microcosmos, un simbólico espejo del universo; todo según Tennyson, lo sería. Todo, hasta el intolerable Zahir" (Borges, El Aleph: 130)

El mismo Borges afirma la naturaleza mística de la temática que se desarrolla en su cuento al concluirlo recordando a los místicos musulmanes (los sufíes): “[...] Para perderse en Dios, los sufíes repiten su propio nombre a los noventa y nueve nombres divinos hasta que éstos ya nada quieren decir. Yo anhelo recorrer esa senda. Quizá yo acabe por gastar el Zahir a fuerza de pensarlo y de repensarlo; quizá detrás de la moneda esté Dios" (Borges, El Aleph: 132).

Zahir es un objeto inmortal y enloquecedor que resume y anula la multiplicidad de las apariencias, y ofrece la posibilidad de acceder a los secretos del universo. Refiriéndose a su cuento Zahir Borges dice lo siguiente:

'El Zahir' versa sobre... una inolvidable moneda de 20 céntimos. Escribí ese cuento partiendo de la palabra 'inolvidable' simplemente, porque leí en alguna parte: ¡deberías oír cantar a Fulano de tal, es algo inolvidable! y entonces pensé ¿qué ocurriría si existiese algo realmente inolvidable? porque a mí me interesan mucho

las palabras, como muy bien puede haberse dado cuenta (Borges el palabrista: 97).

La declaración que hace Borges al final de esta cita, demuestra el excesivo interés del argentino por las palabras. Juan Manuel Velasco Rami subraya este punto cuando testimonia: “Borges quería creer en otra vida con libros, después de la muerte. No creía, desde luego, en una existencia sin ellos, en un mundo sin palabras escritas, sin negro sobre blanco" (Velasco Rami, 1986: 9).

Borges crea una relación profunda con las letras y los libros, y piensa que cualquier objeto adquiere su forma a partir de su nombre, como el caso del Zahir. Por ejemplo, en la palabra rosa se da el sentido de rosa. Esta sensación particular sigue siendo existente aun después de que Borges perdiera el sentido de la vista. Pues, en la oscuridad total, imagina el mundo como un libro edificado por letras indescifrables, y a partir de ahí, interviene el sueño como mejor medio para percibir un desfile de imágenes. En relación a esto, Borges prosigue el mismo camino trazado por los sufíes quienes se interesan en mayor parte por las letras del alfabeto árabe que se dan en algunos primeros versículos del Corán; además de los nombres de Dios.

Luce López-Baralt anota que antes de acercarse a la contemplación de la otra cara de su moneda simbólica, el Borges ficcionalizado del Zahir nos anuncia que, como los sufíes, para prepararse al desasosegante encuentro con el Todo, quiere repetir el mantra, su propio nombre o los noventa y nueve nombres de Dios. Y entonces es cuando estamos preparados para comprender por qué Borges nunca pudo asegurar al lector, que lo que subyacía en El Zahir fuese realmente "Dios", es decir, la palabra "Dios". El Zahir es el símbolo místico más respetuoso de todos los que haya podido acuñar Borges (López-Baralt, 1999: 63-64).

El Aleph es otro cuento borgiano, que se basa en la contemplación y la meditación filosófica. La primera pista que relaciona este cuento con la cultura arabo-islámica, es su título: la primera letra del alifato (alfabeto) árabe.

Este cuento está basado, como en el caso de Zahir en la muerte de una mujer. En El Aleph, tras diez años de la muerte de Beatriz Viterbo, se produce la aparición del Aleph, ya que el hermano de Beatriz, Carlos Argentino, descubre en el sótano de su casa una extraordinaria esfera que contiene el universo. “[...] vi en el Aleph la tierra, y en la tierra otra vez el Aleph y en el Aleph la tierra, vi mi cara y mis vísceras, vi tu cara, y sentí vértigo y lloré, porque mis ojos habían visto ese objeto secreto y conjetural, cuyo nombre usurpan los hombres, pero que ningún hombre ha mirado: el inconcebible universo" (Borges, El Aleph: 194)

Borges en este Aleph ve un universo infinito siguiendo el mismo sistema elaborado por el practicante sufí, quien revela un punto que contiene esa variedad infinita. Para ello, el mundo pierde su principio y fin, y se convierte en un volumen esférico en donde los hombres son escritos. Por consiguiente, ya no será el mundo sino el milagroso Aleph. Este prodigioso modelo del cosmos, contiene toda la gama de escuelas filosóficas como el idealismo, el misticismo, etc. En su intento de interpretar el incógnito Aleph, José Miguel Oviedo apunta:

El asunto examinado en El Aleph es básicamente el mismo que el de Funes el memorioso, con la variante en este caso de que el infinito no es una facultad mental de proporciones sobrehumanas, sino un objeto, una manifestación concreta y localizable de la totalidad del mundo real [...] El gran proyecto literario de Daner (protagonista de El Aleph) es insensato: quiere escribir un inmenso poema narrativo que no sólo sea una copia exacta del universo entero, sino que absorba toc . literatura anterior a él [...] el Aleph es una visión mistica a la vez que infernal, etc.
(Oviedo, 2001: 34-35). 
Por su parte, Borges evoca esta misma alucinación mística en su cuento informando: “¿Cómo transmitir a los otros el infinito Aleph, que mi temerosa memoria apenas abarca? los místicos, en análogo trance, prodigan los emblemas: para significar la divinidad, un persa habla de un pájaro que de algún modo es todos los pájaros" (Borges, El Aleph: 191).

Los tres cuentos anteriores de Borges, prueban sin duda cómo éste intenta trascender la imagen del mundo y del ser humano. Así, rememora varias escuelas del pensamiento universal entre las que cabe el conocimiento sufí de los musulmanes, mediante el cual Borges revela estéticamente este estado de la persona que se dedica a un tipo de contemplación para unirse inefablemente a la divinidad y al universo. De esta manera, en Borges cualquier atributo divino como el conocimiento y la inmortalidad, se relacionan inmediatamente con la disolución de la personalidad. Dicha potencialidad quita al personaje su ser, y deja de ser un ente determinado para convertirse en arquetipo que se iguala al universo. Podemos concluir que los personajes de los cuentos de Borges, tienen el mismo objetivo de los místicos: el conocimiento exacto de Dios y de la realidad absoluta. En los cuentos de Borges Dios está sustituido por símbolos como Almótasim, El Zahir o El Aleph

\section{REFERENCIAS BIBLIOGRÁFICAS}

Barnstone, W., "The secret island", en Borges at Eighty, conversations with Jorge Luis Borges, Bloomington, Indiana University Press, 1982.

Borges, J. L., "El acercamiento a Almotásim”, en Historia de la eternidad.

----, “La biblioteca de Babel”, en Ficciones.

---, "El Zahir", en El Aleph.

Echavarría, A., Lengua y literatura de Borges, Barcelona, Ariel, 1983.

Gónzalez Pérez, A., "Borges y las fronteras del cuento", en El cuento hispanoamericano (E. Pupo Walter, coord.), Madrid, Castalia, 1995

Guibert, R. , "Borges habla de Borges", en Jorge Luis Borges (ed. Jaime Alazraki), Madrid, Taurus, 1986.

Kodama de Borges, M., "Jorge Luis Borges y la experiencia mística", en El sol a medianoche: la experiencia mística: tradición y modernidad, Madrid, Trotta, 1996.

López-Baralt, L., “Borges o la mística del silencio: lo que había del otro lado del Zahir", en Jorge Luis Borges: Pensamiento y saber en el siglo XX, (ed. Alfonso de Toro y Fernando de Toro), Frankfurt am Main, Vervuert, 1999.

López-Baralt, L. y Báez, E. R., “¿Vivió Jorge Luis Borges la experiencia mística del Aleph?", en El sol a medianoche: la experiencia mística: tradición y modernidad, Madrid, Trotta, 1996.
Oviedo, J. M., Historia de la literatura hispanoamericana, 4, De Borges al presente, Madrid, Alianza, 2001

Velasco Rami, J. M., “Borges”, en Borges, Madrid, Biblioteca Nacional, 1986. 